\title{
Prevalence and severity of gingivitis in school students aged 6-11 years in Tafelah Governorate, South Jordan: results of the survey executed by National Woman's Health Care Center
}

\author{
Rania Rodan ${ }^{1}$, Feryal Khlaifat ${ }^{2}$, Leena Smadi ${ }^{*}$, Reem Azab ${ }^{4}$ and Asma Abdalmohdi ${ }^{5}$
}

\begin{abstract}
Background: A cross-sectional census was conducted on 994 public school students aged 6-11 years living in 3 different parts of Tafeleh Governorate - South of Jordan, to determine the prevalence, and severity of gingivitis and to evaluate the oral hygiene habits among them as a part a survey executed by National Woman's Health Care Center. All students were examined for gingival index (Gl) and plaque index (PI), information about oral hygiene habits was recorded.

Results: Only $29.8 \%$ had healthy gingiva, $38.5 \%$ had mild gingivitis, $31.4 \%$ had moderate gingivitis, and $0.3 \%$ had severe gingivitis. The difference between both genders was not statistically significant $P>0.05 .36 .8 \%$ of the examined students never brushed their teeth. Average gingival index (GI) and average plaque index (PI) were 0.77 and 0.61 respectively.

Conclusions: Fair oral hygiene with mild to moderate gingivitis is highly prevalent among Tafelah school children. This study indicated that oral health status among schoolchildren in Tafelah is poor and needs to be improved. Longterm school based oral health education programme is highly recommended.
\end{abstract}

Keywords: Gingivitis, Prevalence, Oral hygiene, Gingival index, Plaque index

\section{Background}

Periodontal diseases are the ones of the most prevalent oral diseases that get its roots early in childhood $[1,2]$. As a consequence of these diseases, if they are not treated on time, the destructive processes are progress in both solid and soft tissues together with losing teeth [3].

Adequate daily removal of dental plaque prevents periodontal diseases and dental caries [3]. The most common and effective way to promote oral hygiene is tooth-brushing; therefore brushing is recommended to be adopted as a habit, which is repeated every morning and evening, at

\footnotetext{
*Correspondence: alsomadi@yahoo.com

${ }^{3}$ Department of Conservative Dentistry, University of Jordan, P.O

Box 855066, Amman 11855, Jordan

Full list of author information is available at the end of the article
}

least twice a day. In addition to improved oral hygiene, which prevents periodontal diseases, frequent brushing with fluoride toothpaste increases the resistance of dentition to dental caries $[4,5]$.

Tooth brushing and other behaviors that comprise young people's lifestyles may directly or indirectly impinge on their health in the short or long term. Most of behavioral patterns were established in early childhood. Oral health behavior may constitute an integral part of an individual's lifestyle. It is essential to develop an effective education programs for oral health and practice targeted at young people.

Periodontal diseases including gingivitis and periodontitis are serious infection that if left untreated can lead to tooth loss. Gingivitis is reversible with professional 
treatment and good oral home care, whereas periodontitis is irreversible as this progress with destruction of bone. Untreated gingivitis can advance to periodontitis. Hence if gingivitis and periodontitis are assessed in an early stage it will minimize the chance of tooth loss. Epidemiological studies are helpful in planning and implementing oral health programs. This would help in combating these diseases.

According to the World Health Organization (WHO), oral health is integral to general health and essential for well-being [6]. Surveillance of oral health on community level thus has to be done at regular intervals.

One of the tasks of the Jordanian National Woman's Health Care Center is to assess the health status and needs of the underprivileged communities throughout Jordan by collection and interpretation of reliable health information.

Tafelah is one of these communities, (Fig. 1) it is a governorate in south of Jordan with a population estimated by the Department of Statistics of Jordan at the end of year 2012 to be 89,400 , which account for $1.4 \%$ of Jordan Population (of them 45,500 males and 43,900 females). Tafelah is divided into three districts: Tafelah District (62.3\% of population), Bsaira District (25.7 \%) and Hasa District (12\%).

The number of schools in Tafelah is 48,41 of them are for boys and rest are for girls accommodate 26,548 students (13,085 girls and 13,463 boys). The population of Tafelah is served by 16 dental clinic distributed throughout the governorate [7].

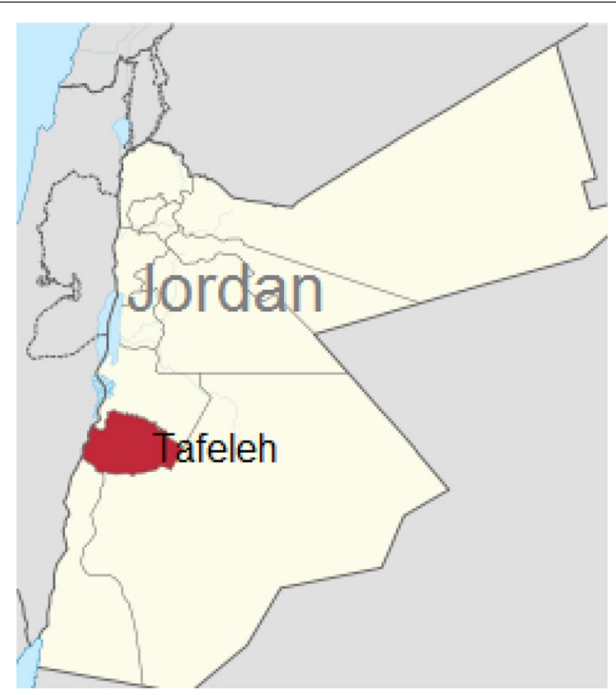

Fig. 1 Tafelah Province: this map shows the location of Tafelah province within Jordan, it shows also the relative size of this province to the total size of Jordan. Source https://upload.wikimedia.org/wikipedia/commons/2/25/Tafilah_in_Jordan.svg
The Oral Health Survey (OHS) 2014 for students aged 6-11 years of age was conducted at Tafelah Governorate schools (south of Jordan) to obtain relevant information on both the oral health condition of the students in this underprivileged area of Jordan and to assess the oral health related behaviors of the students in this area. The survey focuses on two most common but preventable oral diseases, tooth decay (dental caries) [8] and gum disease (periodontal disease), which affect many students; in this article we will review the results of gum disease part of the survey.

\section{Methods}

The survey methodology comprised of a series of fieldwork surveys which were conducted from October 2013 through March 2014. The survey includes students aged 6-11 years of age in six public schools within the governorate (distributed between all districts).The schools selection was based on the two largest schools per district, these schools include classes with mixed gender (grade 1-grade 4) after which mixed classes are not allowed and male students have to move to a boys only schools, all students examined after grade 4 were girls (age group 10-11).

The study protocol was approved by the ethical committee at Ministry Of Health. Due to many logistic barriers it was difficult to get written parents' permission for each examined student individually, though all parents were informed by a letter sent with their children informing them of the screening and examination which will be done as part of Ministry of Health, Ministry of Education and the National Women Health Care cooperation programme. We did not have any single refusal or objections from students' parents; the ethical committee was satisfied with this arrangement.

The clinical examination was carried out by three dentists (examiners) all through the survey. The clinical judgment differences were minimized through pre- survey training for all examiners to homogenize and standardize the examination. Information on the behavior of students was collected using a questionnaire which was completed by the students themselves with the assistance of specially trained dental nurse. Before the survey, the draft questionnaire was pre-evaluated by dentists and dental care nurses working for the School Dental Care Service of the Ministry of Health. Several revisions were made on the questionnaire before it was finalized. Students were examined in a mobile dental clinic which is fully equipped with all the necessary examination instruments, cross infection control methods.

In the process of the research, all the schoolchildren were interviewed according to a standard questionnaire 
(Additional file 1). Clinical examinations were carried out according to World Health Organization (WHO) methods [9]. A mouth mirror and a WHO ball-tip probe were used for the examination. Oral plaque was estimated by running the side of the probe along the teeth surfaces. The children were examined for oral hygiene status, gingival conditions and dental caries. Oral hygiene was evaluated by examining the dental plaque present on the inner and outer aspects of the six index teeth, using the criteria of the plaque index of Silness and Löe [10]. The six indexed teeth are: upper right first molar, upper right lateral incisor, upper left first premolar, the lower right first premolar, the lower left lateral incisor and first molar. Missing teeth are not substituted. The gingival condition was determined for the same teeth using the criteria of the gingival index of Löe and Silness [11].

Table 1 shows the criteria used for plaque index according to Silness-Löe.

Objective research was performed evaluating the state of oral hygiene during the examination as follows: Good (plaque index 0.0 i.e. absence of plaque), Fair (plaque index 0.1-1.9 i.e. presence of plaque) Bad (plaque index 2.0-3.0 i.e. plaque seen by naked eye) [12].

The gingival index, given by Löe and Silness [9] was used for recording the severity of gingivitis. Gingival index, given by Loe and Silness 1963 measures severity of gingivitis on a scale ranging from 0.1 to 3.0 (0.1-1.0: mild gingivitis, 1.1-2.0: moderate gingivitis, and 2.1-3.0: severe gingivitis) $[13,14]$.

Table 2 shows the criteria used for gingival index according to Löe and Silness 1963.

Statistical analysis The analysis of the data was performed using SPSS 20.0 for Windows (SPSS Inc., Chicago, IL, USA).

\section{Results}

\section{Demographic data}

The sample population was 995 students, $64 \%$ of them were females distributed almost equally over the three districts, and the students were examined in the 6 schools of the three districts.

\section{Oral hygiene behavior and status}

Figure 2 shows that $36.8 \%$ of the interviewed students stated that they never brushed their teeth, $19.4 \%$ brush their teeth once per day, $34.8 \%$ twice daily, $9.0 \%$ three times a day. According to plaque index $34.5 \%$ was considered to have good oral hygiene (plaque index 0.0 ), $61.5 \%$ was considered to have Fair oral hygiene (plaque index $0.1-1.9$ ) and $4.0 \%$ was considered to have bad oral hygiene (plaque index 2.0-3.0). (Figure 3) The mean plaque index was $0.61 \pm 0.57$ for the whole sample, the difference between both genders was not statistically significant.

\section{Oral health status}

Among the students examined $70.2 \%$ had gingivitis. According to gingival index $29.8 \%$ had healthy gingiva, $38.5 \%$ had mild gingivitis (GI $0.1-1.0$ ), $31.4 \%$ had moderate gingivitis (GI 1.1-2.0), and $0.3 \%$ had severe gingivitis (GI 2.1-3.0). (Figure 4) The mean gingival index was $0.77 \pm 0.68$ for both genders.

\section{Discussion and conclusions}

In Jordan very few studies looked at oral health among school children, all of them neither examined oral health at neither south of Jordan nor studied specifically prevalence of gingivitis in primary schools [15-18].

Table 1 Criteria used for plaque index (PI)

\begin{tabular}{|c|c|}
\hline Score & Criteria \\
\hline 0 & No plaque \\
\hline 1 & $\begin{array}{l}\text { A film of plaque adhering to the free gingival margin and adjacent area of the tooth. The plaque may be seen in situ only after appli- } \\
\text { cation of disclosing solution or by using the probe on the tooth surface }\end{array}$ \\
\hline 2 & $\begin{array}{l}\text { Moderate accumulation of soft deposit s within the gingival pocket, or the tooth and gingival margin which can be seen with the } \\
\text { naked eye }\end{array}$ \\
\hline 3 & Abundance of soft matter within the gingival pocket and/or on the tooth and gingival margin \\
\hline
\end{tabular}

Table 2 Criteria used for gingival index (GI)

\begin{tabular}{ll}
\hline Score & Criteria \\
\hline 0 & No inflammation \\
1 & Mild inflammation, slight change in color, slight edema, no bleeding on probing \\
2 & Moderate inflammation, moderate glazing, redness, bleeding on probing \\
3 & Severe inflammation, marked redness and hypertrophy, ulceration, tendency to spontaneous bleeding \\
\hline
\end{tabular}




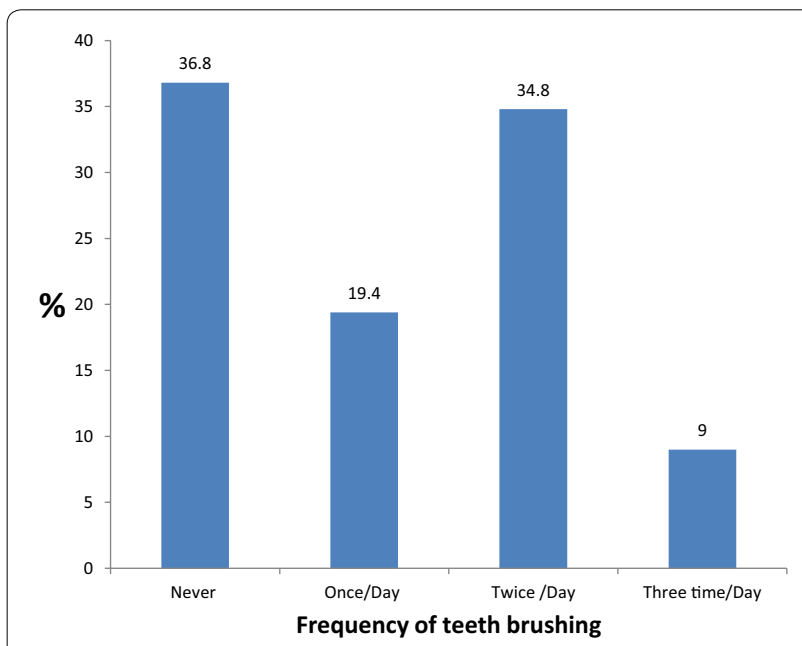

Fig. 2 Frequency of teeth brushing. The frequency of teeth brushing as reported by students extracted from their answer using a preprepared questionnaire

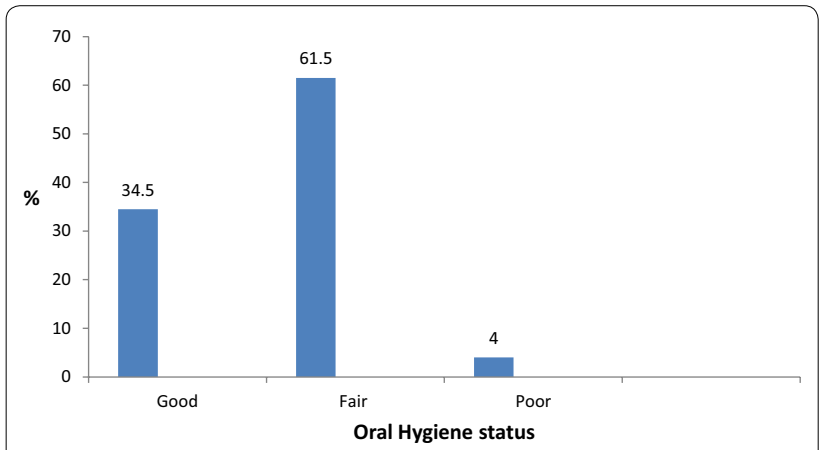

Fig. 3 Oral hygiene status according to plaque index (PI). The oral hygiene status is demonstrated using the plaque index (PI) for all students examined during the survey, the status was classified as Good, Fair and Poor

The present study is among the foremost efforts to determine the oral behaviors and prevalence and severity of gingivitis in school children aged 6-11 in one of the most unprivileged areas of Jordan.

This survey was also conducted to assess the need to start a local campaign to raise the public awareness for oral hygiene and the need to modify polices for early access to preventive dental services among school children.

The results of this surveys shows that $69.9 \%$ of school children aged 6-11 had gingivitis of mild to moderate severity. Those results are similar to the results of other parts of the word of similar cultural and socioeconomic status. A recent survey in Lucknow/India of school children aged 8-16 have shown that $71.11 \%$ of school children aged 8-10 suffered of gingivitis of mostly mild to moderate severity [13]. Another survey on Lithuanian

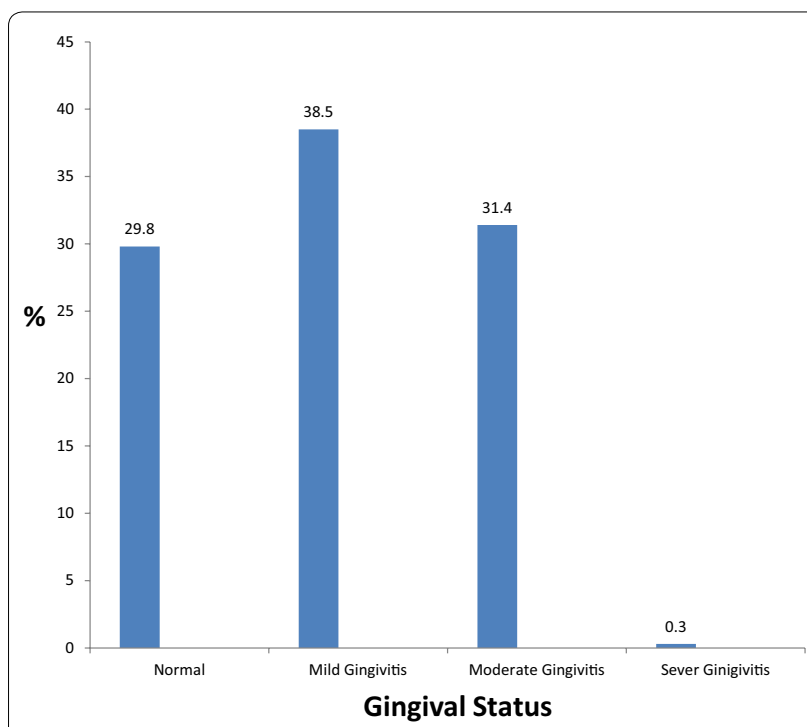

Fig. 4 Gingival status according to gingival index (Gl). The Gingival status is demonstrated using the gingival index (Gl) for all students examined during the survey, the status was classified as Normal, Mild Gingivitis, Moderate Gingivitis, and Sever Gingivitis

school children of older age group of 11-15 have also showed that $>50 \%$ of them complaining of gum bleeding [19]. In Kaunas a survey have shown that $59.6 \%$ of school children aged 6-8 suffered of light gingivitis [20]. In Tehran it was shown that $87.7 \%$ of schoolchildren aged 9-13 had gingivitis [21]. On the other hand a survey on periodontal status of Greek 12 year's old population has shown that $41.5 \%$ had bleeding on probing [22]. Gingival bleeding was found in $32.8 \%$ of the children aged 6-12 years from the Danube Delta Biosphere Reserve [23].

Gingival index and plaque index were chosen for this study as it has been widely used to evaluate the level gingival inflammation and the level of oral cleanliness in epidemiological studies [14]. This relatively simple assessment is fairly reproducible, easy to use since the criteria are objective and the examinations can be carried out quickly with a high level of reproducibility and with minimum training.

This study revealed that the mean plaque index and gingival index for the total subjects was 0.61 and 0.77 respectively. Those results were interpreted that school children of this age group 6-11 had fair oral hygiene with mild gingivitis. Regarding gender variations, the difference was statistically non-significant, $(p=0.636$ for PI and 0.790 for GI) between both genders. These findings disagreed with earlier studies in 13-14 year old Northern Jordanian schoolchildren that reported plaque index scores were 1.82 and 1.63 during 1993 and 1999 respectively [24]. Furthermore, gingival index scores reported 
in the same study [24] were 1.89 in 1993 and 1.67 in 1999 which were also higher than the figure found in this study. A more recent study took place in 2006 for 14-15 year old schoolchildren in Jerash district and reported a plaque index score of 1.46 and gingival index score of 1.56 [15]. But these results are still higher than results obtained in this study. The higher results can be explained by the difference in the age group, a previous cross-sectional study of gingival health status among 5- and 12-year-old children in Yemen showed increased prevalence and severity of gingivitis in a 12 years old children when compared to a 5 years old children as the plaque index increased as well [14]. Regarding gender variations, a previous study that described trends in oral health in Jordanian male and female schoolchildren, showed that boys had higher plaque and gingival scores than girls within this age group. This gender difference with regard to plaque and gingival scores may be related to the patterns of personal oral hygiene, hormonal changes occurring during puberty and grooming effect at this age [24]. Another study found that girls scored more favorably on behavioral measures, showed more interest in oral health, and perceived their own oral health to be good to a higher degree than did boys [19]. Those gender differences were not obvious among school children surveyed in this study.

With regard to hormonal changes occurring during puberty that affect the gingiva, several cross-sectional studies have demonstrated an increase in gingival inflammation without an accompanying increase in plaque levels during puberty [25].

Tooth brushing is not common or routinely practiced in schoolchildren in Tafelah. The proportion of children reported to be brushing at least once to twice per day was $54.2 \%$ in the Tafelah health survey. Although there is good evidence to recommend tooth brushing twice daily for control of plaque and gingivitis [5], $36.8 \%$ of 6-11 year-old children reported that they never brushed their teeth. Routine dental visits are not a habit for the children in Tafelah. Results showed that $85.9 \%$ of the surveyed school children had never been to a dentist.

Unlike the results of this survey where frequency of teeth brushing was similar in boys and girls several other epidemiological surveys have shown that the factor most consistently associated with teeth brushing and other oral hygiene habits frequency was gender. Girls were more concerned about their personal hygiene than boys.

They have also shown the importance of social-economic background for determining children's tooth brushing behavior [26]. Children from rural areas reported higher percentage of inadequate oral hygiene than children from urban areas [19]. Similar results were also demonstrated in public schools when compared to private schools [27] and in lower socio-economic background when compared to a higher socio- economic background [26]. As all the surveyed students were from public schools and almost of similar socio- economic background this factor was not investigated in our survey.

Oral health education is an important aspect. All students should get at least one oral health education lesson with a supervised tooth brushing exercise every school year. Oral health education sessions should be organized for parents and pregnant mothers and dental health education programmes should be conducted for schoolteachers.

Post-intervention 9 months oral health education on oral hygiene knowledge, practices, plaque control and gingival health of 13- to 15-year-old school children in Bangalore city, there was significant improvement in oral hygiene knowledge and practices in experimental groups. There were significant reductions in mean plaque index and gingival index scores in the experimental groups [28]. Plaque and Gingival score reductions were highly significant after a school dental education program in improving oral health knowledge and oral hygiene practices and status of 12- to 13-year-old school children, and were not influenced by the socioeconomic status. When oral health knowledge was evaluated, highly significant changes were seen in intervention schools; more significantly in schools receiving more frequent interventions [29]. A cluster randomized controlled trial education programme for 6-year-olds concluded that oral hygiene instruction to 6-year-old children and their parents improves their dental health [30].

Prevention and treatment of early stages of periodontal diseases are relatively simple and very effective. In many cases it is enough to have the social education and instructions for correct and regular oral hygiene. The preventive component of lifestyle should be induced and accepted at a young age. Epidemiological investigations of periodontal status and oral hygiene are an important part of such preventive program.

- Information provided by the present study can be used as preliminary data and further large scale epidemiological studies can be under taken to assess and confirm other dental diseases and their associated risk factors in Tafelah, Jordan. School dental health programs and dental camps at school level are necessary in this region and they should be conducted at regular intervals, because children in this region do not have accessed to standard dental care and treatment. Because schools children do not know much about dental diseases, methods of their prevention and to maintain proper oral hygiene, therefore education and 
motivation of children is of paramount important in this region. Teachers and parents should be taught and encourage to inculcate healthy life style habits in children. However education itself is not enough to bring tangible changes in behavior change. Another opportunity to utilize the school setting would be to ensure lifelong skills such as school based tooth brushing and hand washing. It is worth mentioning that we utilize this survey as an opportunity to organize oral health education lessons for the surveyed school children and their school teachers to increases dental awareness and to enhance oral hygiene methods by demonstrating the correct frequency, method and duration of teeth brushing. Intersectoral coordination with education, government sectors and development of public health policy has profound effect in improving the health of the community people.

\section{Additional file}

Additional file 1. Questionnaire answered by students and examinatiuon carried out by dentists.

\section{Abbreviations}

Gl: gingival index; Pl: plaque index; WHO: World Health Organization (WHO); OHS: oral health survey (ohs).

\section{Authors' contributions}

RR: participated in formatting the conception, design, and acquisition of data, analysis and interpretation of data. FK participated in study design analysis and data collection. LS: participated in formatting the conception, design, acquisition of data, analysis, interpretation of data and writing up the manuscript. RA participated in study design, analysis. AA participated in study design, data collection and logistic support and coordination. All authors read and approved the final manuscript.

\section{Author details}

${ }^{1}$ Royal Medical Services, P.O Box 391, Salt 19110, Jordan. ${ }^{2}$ Ministry of Health, P.O Box 1040, Amman 11941, Jordan. ${ }^{3}$ Department of Conservative Dentistry, University of Jordan, P.O Box 855066, Amman 11855, Jordan. ${ }^{4}$ Ministry of Health, P.O Box 86, Amman 11118, Jordan. ${ }^{5}$ Head of Planning, Research and Information Department, National Woman's Health Care Center, P.O Box 723, Amman 11831, Jordan.

\section{Acknowledgements}

The authors would like to thank the National Woman's Health Care Center- Jordan who organized and executed this survey in collaboration with Jordanian Ministry of health, Jordanian Ministry of Education and Jordanian Royal Medical Services who used their resources and staff to conduct the survey and for their efforts to make the data of this survey available for research and publication.

\section{Competing interests}

The authors declare that they have no competing interests.

Received: 8 January 2015 Accepted: 28 September 2015

Published online: 09 November 2015

\section{References}

1. Pilot T, Miyazaki H. Global results: 15 years of CPITN epidemiology. Intern Dental J. 1994;44:553-60.

2. Oh T-J, Eber R, Wang H-L. Periodontal diseases in the child and adolescent. J Clin Periodontol. 2002;29:400-10.

3. Axelsson P. An introduction to risk prediction and preventive dentistry. USA: Quintessence Publishing Co Inc.; 1999. p. 159.

4. Murray JJ. Prevention of oral disease. Oxford: Oxford University Press; 1996. p. 280.

5. Cury JA, Tenuta LM. Evidence-based recommendation on toothpaste use. Braz Oral Res. 2014;28:1-7.

6. Sheiham A. Oral health, general health and quality of life. Bull World Health Organ. 2005;83:644.

7. Department of Statistics, Jordan Statistical yearbook. 2012.

8. Smadi L, Azab R, Rodan R, Khlaifat F, Abdalmohdi A. Prevalence and severity of dental caries in school students aged 6-11 years in Tafelah Governorate-South Jordan: results of National Woman's Health Care Center Survey. Oral Health Dent Manag. 2015;1:1-6.

9. World Health Organization. Oral health surveys: basic methods, 5th edn. 2013.

10. Silness J, Löe H. Periodontal disease in pregnancy ii. Correlation between oral hygiene and periodontal condition. Acta Odontol Scand. 1964;22:121-35.

11. Löe H, Silness J. Periodontal disease in pregnancy. 1. Prevalence and severity. Acta Odontol Scand. 1963;21:53.

12. Al-Mutawa SA, Shyama IM, Al-Duwairi IY, Soparkar P. Oral hygiene status of Kuwaiti schoolchildren. East Mediter Health J. 2011;17:387-91.

13. Singh AK. Prevalence of gingivitis and periodontitis among schools children in Lucknow region of Uttar Pradesh, India. IOSR J Dent Med Sci. 2014;13:21-3.

14. Al-Haddad KA, Ibrahim YT, Al-Haddad AM, Al-Hebshi NN. Assessment of gingival health status among 5- and 12-year-old children in Yemen: a cross-sectional study. ISRN Dent. 2013;26:1-7.

15. El-Qaderi SS, Quteish Ta'ani D. Dental plaque, caries prevalence and gingival conditions of 14- to 15-year-old schoolchildren in Jerash District, Jordan. Int J Dent Hyg. 2006;4(3):150-3.

16. Al-Omiri MK, Al-Wahadni AM, Saeed KN. Oral health attitudes, knowledge, and behavior among school children in North Jordan. J Dent Educ. 2006;70(2):179-87.

17. Taani DS. Oral health in Jordan. Int Dent J. 2004;54(6 Suppl 1):395-400.

18. Taani DQ, Alhaija ES. Self-assessed bleeding as an indicator of gingival health among 12- to 14-year-old children. J Oral Rehabil. 2003;30(1):78-81.

19. Zaborskyte A, Bendoraitiene E. Oral hygiene habits and complaints of gum bleeding among schoolchildren in Lithuania. Stomatologija. 2003;5:31-6.

20. Pauraite J, Milciuviene S, Sakalauskiene J. The prevalence of gingivitis among 4-16 year old schoolchildren in Kaunas. Stomatol Baltic Dent Maxillofac J. 2003;5:97-100.

21. Jessri M, Jessri M, Rashidkhani B, Kimiagar SM. Oral health behaviors in relation to caries and gingivitis in primary-school children in Tehran, 2008. East Mediterr Health J. 2013;19(6):527-34.

22. Vadiakas G, Oulis CJ, Tsinidou K, Mamai-Homata E, Polychronopoulou A. Oral hygiene and periodontal status of 12 and 15-year-old Greek adolescents. A national pathfinder survey. Eur Arch Paediatr Dent. 2012;13(1):11-20.

23. Jipa IT, Amariei Cl. Oral health status of children aged 6-12 years from the Danube delta biosphere reserve. Oral Health Dent Manag. 2012;11(1):39-45.

24. Quteish Taani D. Trends in oral hygiene, gingival status and dental caries experience in 13-14-year-old Jordanian school children between 1993 and 1999. Int Dent J. 2001;51:277-81.

25. Mariotti A. Sex steroid hormones and cell dynamics in the periodontium. Crit Rev Oral Biol Med. 1994;5:27-53.

26. Powell RN, Gilhooly JT, McKenna ER. Prevalence and distribution of gingivitis and dental caries in children aged 6-12 years in Brisbane primary schools. Community Dent Oral Epidemiol. 1986;14(2):110-4. 
27. Sukhabogi J, Shekar C, Hameed I, Ramana I, Sandhu G. Oral health status among 12- and 15-year-old children from government and private schools in Hyderabad, Andhra Pradesh, India. Ann Med Health Sci Res. 2014;4(Suppl 3):272-7.

28. D'Cruz AM, Aradhya S. Impact of oral health education on oral hygiene knowledge, practices, plaque control and gingival health of 13- to 15-year-old school children in Bangalore city. Int J Dent Hyg. 2013;11(2):126-33.
29. Shenoy RP, Sequeira PS. Effectiveness of a school dental education program in improving oral health knowledge and oral hygiene practices and status of 12- to 13-year-old school children. Indian J Dent Res. 2010;21(2):253-9.

30. Esfahanizadeh N. Dental health education programme for 6-yearolds: a cluster randomised controlled trial. Eur J Paediatr Dent. 2011;12(3):167-70.

Submit your next manuscript to BioMed Central and take full advantage of:

- Convenient online submission

- Thorough peer review

- No space constraints or color figure charges

- Immediate publication on acceptance

- Inclusion in PubMed, CAS, Scopus and Google Scholar

- Research which is freely available for redistribution

Submit your manuscript at

www.biomedcentral.com/submit

(O) Biomed Central 